\title{
Social Transparency in Enterprise Information Systems: Peculiarities and Assessment Factors
}

\author{
Tahani Alsaedi, Angelos Stefanidis, Keith Phalp, Raian Ali \\ Faculty of Science and Technology \\ Bournemouth, UK \\ \{talsaedi, astefanidis, kphalp, rali\}@ bournemouth.ac.uk
}

\begin{abstract}
Social transparency within an organisation refers to the intentional sharing by individuals of information relating to themselves and their group to others in the workplace. This includes announcing personal interests, activity status, priorities and personal achievements. Such transparency is typically intended to increase relatedness, motivation and trust amongst colleagues. Social networking features are being embedded within organisational information systems, allowing an online version of social transparency. An ad-hoc implementation of such transparency can pose issues such as information overload, motivating unwanted grouping amongst colleagues and increasing pressure to perform in a certain manner. This results in organisational problems such as reduced productivity, unproductive competition and high turnover rates. Our ultimate aim is to address these issues by proposing an assessment method for online social transparency to detect and minimise its negative impact on employees and organisations. In this paper, we report on empirical study results and present (1) a set of peculiarities of implementing online transparency in enterprise information systems and (2) a set of essential factors that relate to the assessment process.
\end{abstract}

Keywords: Social Transparency, Social Computing, Enterprise Social Software, Organisational Information Systems

\section{INTRODUCTION}

Enterprise social software denotes a family of collaborative tool that allows enterprise members to communicate in real-time about their activity streams, assigned goals, work priorities, work progress and work done jointly with others [1]. Examples of SSE's features are discussion forums, user-profiles and files sharing. In the context of such software and enterprise information systems in general, we define social transparency as the use of online spaces by individuals and groups to communicate their own information on a voluntary basis to support positive work ethics such as building organisational trust [2], maintaining organisational ethics, reducing misdeeds [3] and increasing employees' engagement and motivation [4]. We also note that such kinds of transparency may have potential sideeffects in terms of individual wellbeing, performance, morale and the general perception of the work environment. For example, a high level of transparency between team members can lead to risks relating to stressful competition and information overload [5].

From the perspective of human behaviour in information systems, transparency is conceptualised as "Understanding an other's intention and goals" [6], "being informed" [7] and "freely volunteering information [8]". Organisations adopted transparency as a core value and embedded it in their culture and style of internal communications for various reasons such as improving relations between internal actors. An open culture of internal knowledge sharing is meant to increase employees motivation to engage in their job, which in turn leads to performance improvements [9]. Transparency has been accounted as an essential commodity to restore trust and building relationships [2], improve organisational performance, through motivating its employees [10], and support open decision making [11].

To manage these benefits and minimise negative sideeffects, researchers have studied transparency in different domains to provide several theoretical underpinnings which help explain the complex nature of transparency, mostly from the social and organisational science perspectives. An argumentation framework was proposed as a formal approach to capturing transparency-related requirements in [12]. The authors in [13] argued that software transparency must be based on requirements which will be a baseline for downstream and upstream traceability. They handle the problem of software transparency using the idea of requirements that need to be understandable and readable for both general stakeholders and software developers. Hence, they proposed a transparency measure that represents a substantial step to achieving useful transparency. In [14], a survey was designed to find an effective and efficient way to measure and control the level of transparency in the software development processes. In [15], the authors addressed the issue of providing software system that supports the demand for transparency. They treated transparency as a quality requirement for software systems and, therefore, soft-goal interdependencies graphs [16] have been used to conceptualise transparency and the several quality requirements related to it. Further research led to developing a new modelling language to manage the elicitation of transparency requirements. Authors in [17, 18] proposed TranspLan as a modelling language to capture transparency requirements in business information systems. They provided templates for identifying transparency requirements, and they use algorithms to reason about the consistency and conflicts of the captured requirements.

The quality of transparency and the impact of its flawed implementation are already recognised in various information systems, social computing and requirement engineering (RE) literature, computer support learning or Elearning $[12,17]$. However, there is still a limitation in providing concepts, methods and metrics to aid assessments and identifying risks and mitigating strategies for it. In this paper, we provide preliminary results of our on-going work in this area and our attempts to bridge this gap in the literature. We discuss the peculiarities of social transparency when communicated via online spaces and tools and factors for its assessment. 


\section{RESEARCH METHOD}

There is a paucity of work specifically evaluating transparency levels, quality and risks in enterprise information systems. Therefore, we set out to explore what these aspects are in the first place. As the starting point to developing such approaches, we conducted qualitative research to explore the core set of requirements for social transparency in terms of information content and quality.

A total of 14 individuals participated in two focus group discussions to explore how they view transparency in their workplace information systems, their requirements of it, and how certain modalities and configurations of transparency can contribute to risks for them and their groups. We recruited participants who worked in organisations where their role involved collaborative work with others online. To ensure the diversity of views and opinions, participants were from different affiliations (academic and practical), different fields (psychology, management, media, education, computing) and different ethnicities. The sessions were run over several stages, as presented in Table I. At the beginning of the session, participants were given a presentation to familiarise themselves with the context of the research. We developed four scenarios to cover various aspects of transparency, such as its content (e.g. intentions, plans and status), its presentation (media and interfaces), its timing and relevance. We used them in the session to stimulate discussions. Each scenario included questions to be answered individually before they were discussed with the group. The focus groups were transcribed verbatim to support further analysis. We used a thematic analysis approach by coding the collected data and grouping the codes into themes [19]. We analysed the first focus group to generate the codes related to the assessment factors of social transparency. The second focus group were conducted for further exploration and to confirm the results of the first focus group.

TABLE I. STAGES OF FOCUS GROUP SESSIONS

\begin{tabular}{|l|l|}
\hline \multicolumn{1}{|c|}{ Stage } & \multicolumn{1}{c|}{ Description } \\
\hline Preparation & $\begin{array}{l}\text { Participants were given a presentation about the concept } \\
\text { to familiarise themselves with the context of the } \\
\text { research. }\end{array}$ \\
\hline $\begin{array}{l}\text { Individual } \\
\text { Work }\end{array}$ & $\begin{array}{l}\text { We developed four scenarios to cover various aspects of } \\
\text { transparency: its content (e.g. intentions, plans and } \\
\text { status), its presentation (media and interfaces), its timing, } \\
\text { and intended recipients (social interdependencies). }\end{array}$ \\
\hline Focus Group & $\begin{array}{l}\text { Sub-groups were created to discuss their answers and } \\
\text { points of view }\end{array}$ \\
\hline
\end{tabular}

\section{PECULIARITIES OF ONLINE SOCIAL TRANSPARENCY}

We understand transparency as individual insights into each other's activities and resources. Social transparency applied in enterprise networking software to enable individuals to be aware of the work of others within a workplace environment and to make them available to each other as resources for their activities [20]. In this section, we identified features of online transparency that make it different from face-to-face and other dissemination methods adopted for social communication amongst organisations members. Considering these features makes it necessary to revisit the established principles and knowledge about transparency to reflect its new manifestation when hosted and facilitated via online spaces. In the following, we list these features and elaborate on the peculiarities they introduce to transparency and its management.

\section{- Archivability}

Transparency through online platforms has archivability feature that creates a searchable history of information that is disseminated and exchanged amongst different parties. Considering this feature in the assessment process of online social transparency helps systems analysts, systems engineers alongside with managers and employees to search through a massive volume of archived information to examine the causes of certain kind of risks that stems from sharing social information. For example, when people are transparent about their emotional state, risks like emotion contagion can be detected through data mining.

\section{- Traceability}

Applications that support online transparency may have a feature that records all changes that happened on the original version of the information. Archivability feature of these applications aids managers, systems analysts, system designers as well as employees themselves to mitigate the risks stems from social transparency, such as misunderstanding and denial, by tracing back to find the source of information and the changes that made to it to detect the reason of the risks.

\section{- Trackability}

Transparency through online platforms enables individuals to track their information and its outreach to ensure its delivery to all intended members. Participants stated that transparency trackability through online mediums reduced the risks of the problems like preoccupation and awareness. Trackability also allows information senders to know who received or looked at their information, which in turn helps them to set their expectations or control their next transparency activity. From the system analyst's perspectives, considering trackability in the assessment of social transparency may help in predicting the potentiality of risks occurrence.

\section{- Real-Time}

Unlike face-to-face communication and other classic dissemination methods, communicating transparency through online platforms can provide instantly and real-time information. The time dimension of transparency is one of the crucial factors that need to be considered in designing transparency for situation awareness purposes. In the workplace, maintaining real-time social awareness of the coworkers' context is important for successful cooperation [21]. For example, declaring employees current status in an auto-reply helps colleagues to avoid disturbing them and finding alternatives such as getting assistance from another employee or booking other time slots. Real-time nature of online transparency may also save time and avoid potential delays that may happen in the workplace but can also introduce risks around pressure and Hawthorne effect.

\section{- Mobility}

Online transparency is scalable and can serve distributed groups, staff, departments or organisations and can be accessed through various mobile and stationary devices and applications. Participants revealed that the number of mobile workers continues to grow in their organisations where employees are located in distributed departments, working 
from home or they go on a vacation. Participants in our study emphasised the role of online transparency in facilitating collaboration with colleagues who work remotely. The mobility of accessing online transparency can be considered in the assessment process of online social transparency to mitigate risks that may happen for distributed employees such as misjudgement and misconception in their progress.

\section{- Open accessibility}

Online transparency in organisations has the ability to reach the widest number of staff at the same time. This feature of online transparency shows its significance in saving the time of disseminating social information in large organisations. For example, transparency of employee availability, activities, skills and interests can be accessed by all members of the organisation which can be good from effort and outreach perspective but also risky in terms of retractability and potential abuse and intimidation.

\section{- Unchangeability}

Participants claim that unreliability of face-to-face transparency and other forms of disseminating it such as newsletters and announcement result from the distortion that often happens on the information as it travels through the organisation and their different personnel. The information may be distorted unintentionally by various contexts such as employees' mood, cognitive ability, ethics, time and location. Social transparency, as we defined in this work is related to individual intentions and their socially-related information. Technology allows individuals to disseminate such information directly to other members and avoid distortion occurred through the involvement of different parties.

\section{- Presentation adaptability}

Transparency through online platforms has the flexibility to present the information in different formats (text- audiovideo- graphics) and different time slots based on the recipients' preferences. Providing transparency in a preferable format in a context-sensitive manner (e.g. audio while driving) allows better communication and comprehension of it. Good presentation of online transparency helps to eliminate situations where recipients ignore the information due to its complexity and recipient's busyness. The flexibility of presenting online transparency can also introduce risks of incorrect contextualisation and personalisation. Such processes would also require sensing infrastructure and historical data about staff and their dynamic environment to build their user model and know their preferences.

\section{- Selectability}

Our participants declared that they prefer online transparency due to its select-ability feature that allows them to select the information that suits their interest, skills, goals, tasks and time availability. Using filtering features in online platforms enable recipients to customise others social transparency to benefit from related information only and mitigate risks such as information overload of unwanted information. This can be seen as user-administered personalisation and configuration of transparency.

\section{ONLINE SOCIAL TRANSPARENCY: ASSESSMENT FACTORS}

The concept map in Fig. 1 represents the findings of the study that is meant to provide a baseline for assessing online social transparency. The map is intended to help systems analysts and management assess risks and provide tools to mitigate them. In the following, we present a set of essential factors relating to the assessment process.

\section{- Transparency Recipients}

We found that transparency should be customised based on the role of the recipients and their inter-relationship with the information provider. Assessing transparency recipients focuses on identifying the actors who should receive certain types of information. Questions regarding the assessment of transparency recipients are based on the level of dependency amongst actors, the value of the information to the recipient and the consistency of the information provided with the recipient's work boundaries.

\section{- Transparency Content}

We found that transparency allows members to provide information about their actions, which helps others to maintain mental models of their activities and avoid potential coordination conflicts. In this context, transparency assessment methods must check the content of transparency against the following points:

Content availability: Some issues such as work conflict or misjudgements between peers may occur as a result of a lack of transparency about social and work information. Systems analysts should ask if the availability of certain information would mitigate these issues.

Content relevance: Relevance is defined as "the extent to which information is applicable and helpful for the task at hand" [22]. Irrelevant transparency amongst organisational staff may have an adverse impact on the level and quality of collaboration between them. Therefore, customising the content of transparency can deter the occurrence of potentially associated issues.

Content accessibility: Providing relevant information is not sufficient to make transparency effective. The information must be accessible to the intended actors in their different contexts or work to enable the decision-making process. For example, textual and browsable information is practically inaccessible to someone who is driving.

\section{- Presentation of Information}

The presentation of information refers to the extent to which information is understandable and readable by the intended user [23]. Organisational staff may come from different backgrounds, locations, education levels and cognitive abilities and also have different preferences. The presentation of transparency differs according to the ability of staff to process information for their own purposes. We found that the content of transparency should be presented in an interpretable, easy to understand, consistent and compatible format to the recipients.

\section{- $\quad$ Timeliness of information}

Our analysis revealed that transparency is only effective if the information communicated is timed in a way that enables the recipients to bring about a positive outcome and reaches the recipients when they are ready and able to make a decision. We found that transparency timeliness can be classified according to the relation with the actor's activity, into three categories:

Transparency before the activity: Unmanaged transparency or a lack of transparency before an activity may stem issues 


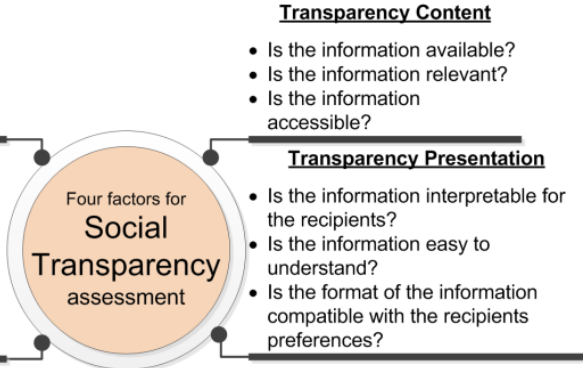
relevant?

\section{Transparency Recipients}

- Do the recipients depend on information providers?

Is the information valuable for the recipients?

- Is the information consistent with the recipient's work ?

Fig.1: Factors for Online Social Transparency Assessment

such as disengagement or a loss of interest in the activity. Transparency before the activity means providing the roles, responsibilities, activeness, genuine interest and interdependencies related to a particular activity.

Transparency during activity: Issues such as delays in progress and stress may result from a lack of transparency about the progress achieved, the status and availability of the resources used, as well as physical or self-obstacles.

Transparency after activity: Transparency after a completed activity may be practised for the purpose of learning and improvement such as voluntary feedback, performance clarification and activity shortness. However, late transparency after an activity may reduce motivation, create a bad impression or result in misjudgement between organisational members.

Real-time transparency: Before, during and after the activity, organisational members may need real-time information that helps accelerate the decision-making process. However, issues such as distraction and a loss of interest may result from untimely transparency.

Frequency of transparency: Similar to real-time transparency, transparency can be undesired if it is practised randomly and with no static frequency. For example, reliability between team members may result from a collective agreement for the frequency of individual transparency between them (e.g. sharing progress achievements at the end of the day).

\section{CONCLUSIONS AND FUTURE WORK}

We presented factors to consider when assessing online social transparency to make relevant information available in a timely manner to the right recipients with minimum adverse effects on other members in the enterprise. We proposed a concept map of such factors considering the nature of the voluntary transparency of social information amongst organisational members. The differentiation of voluntary social transparency as a distinguished class of transparency was motivated by the fact that its neither obligatory nor critical for the business but rather based on the will of actors to communicate their own information to fulfil certain personal goals such as seeking collaboration, promoting their identities, building relationships and raising awareness.In our future work, we will refine and expand these findings and build and verify an assessment framework for it in enterprise information systems.

\section{REFERENCES}

[1] S. Graupner, C. Bartolini, H. Motahari, and D. Mirylenka, "When social media meet the enterprise." In IEEE 16th International
Enterprise Distributed Object Computing Conference, pp. 201-210, 2012.

[2] M. Bandsuch, L. Pate, and J. Thies, "Rebuilding Stakeholder Trust in Business: An Examination of Principle- Centered Leadership and Organizational Transparency in Corporate Governance 1," Business and Society Review, vol. 113, no. 1, pp. 99-127, 2008.

[3] M. Turilli, and L. Floridi, "The ethics of information transparency," Ethics and Information Technology, vol. 11, no. 2, pp. 105-112, 2009.

[4] J. Marlow, and L. A. Dabbish, "Who's the boss?: requester transparency and motivation in a microtask marketplace." In CHI'14 Extended Abstracts on Human Factors in Computing Systems pp. 2533-2538, 2014.

[5] R. L. Laud, and D. H. Schepers, "Beyond transparency: Information overload and a model for intelligibility," Business and Society Review, vol. 114, no. 3, pp. 365-391, 2009.

[6] C. Cornand, and F. Heinemann, "Optimal degree of public information dissemination," The Economic Journal, vol. 118, no. 528, pp. 718-742, 2008.

[7] A. Eggert, and S. Helm, "Exploring the impact of relationship transparency on business relationships: A cross-sectional study among purchasing managers in Germany," Industrial Marketing Management, vol. 32, no. 2, pp. 101-108, 2003.

[8] S. Baker, "The model of the principled advocate and the pathological partisan: A virtue ethics construct of opposing archetypes of public relations and advertising practitioners," Journal of Mass Media Ethics, vol. 23, no. 3, pp. 235-253, 2008.

[9] G. R. Vogelgesang, and P. B. Lester, "How leaders can get results by laying it on the line," Organizational Dynamic, vol. 38, no. 4, pp. 252-260, 2009.

[10] T. McManus, Y. Holtzman, H. Lazarus, J. Anderberg, E. Berggren, and R. Bernshteyn, "Organizational transparency drives company performance," Journal of Management Development, vol. 26, no. 5, pp. 411-417, 2007.

[11] J. de Fine Licht, "Do we really want to know? The potentially negative effect of transparency in decision making on perceived legitimacy," Scandinavian Political Studies, vol. 34, no. 3, pp. 183201, 2011.

[12] M. Serrano, and J. C. S. do Prado Leite, "Capturing transparencyrelated requirements patterns through argumentation." First International Workshop On Requirements Patterns, pp. 32-41, 2011.

[13] J. C. S. do Prado Leite, and C. Cappelli, "Exploring i* Characteristics that Support Software Transparency." In iStar 3rd International i Workshop, pp. 51-54, 2008.

[14] Y.-C. Tu, C. Thomborson, and E. Tempero, "Illusions and perceptions of transparency in software engineering." In 18th AsiaPacific Software Engineering Conference pp. 365-372, 2011.

[15] J. C. S. d. Prado, Leite, Cappelli, and Claudia, "Software transparency," Wirtschaftsinformatik, Vol. 52, No. 3, 2010.

[16] L. Chung, B. A. Nixon, E. Yu, and J. Mylopoulos, Non-functional requirements in software engineering: Springer Science \& Business Media, 2012.

[17] M. Hosseini, A. Shahri, K. Phalp, and R. Ali, "A modelling language for transparency requirements in business information systems." In International Conference on Advanced Information Systems Engineering, pp. 239-254, 2016.

[18] M. Hosseini, A. Shahri, K. Phalp, and R. Ali, "Engineering transparency requirements: A modelling and analysis framework," Information Systems, vol. 74, pp. 3-22, 2018.

[19] V. Braun, and V. Clarke, "Using thematic analysis in psychology," Qualitative research in psychology, vol. 3, no. 2, pp. 77-101, 2006.

[20] C. Dalsgaard, and M. F. Paulsen, "Transparency in cooperative online education," The International Review of Research in Open and Distributed Learning, vol. 10, no. 3, 2009.

[21] J. Y. Chen, K. Procci, M. Boyce, J. Wright, A. Garcia, and M. Barnes, Situation awareness-based agent transparency, Army research lab aberdeen proving ground md human research and engineering directorate, 2014.

[22] R. Y. Wang, and D. M. Strong, "Beyond accuracy: What data quality means to data consumers," Journal of management information systems, vol. 12, no. 4, pp. 5-33, 1996.

[23] Y. W. Lee, D. M. Strong, B. K. Kahn, and R. Y. Wang, "AIMQ: a methodology for information quality assessment," Information \& management, vol. 40, no. 2, pp. 133-146, 2002 